Promoting children's health should be the primary focus of any practice. While DRGs are a hospital reality, implementation of a resource-based relative value scale for physician services seems imminent. This proposed redistribution of medical moneys, being developed by Harvard University through a study commissioned by the Health Care Financing Administration, may be a boost to primary care practitioners and others who provide time-intensive, cognitive-type services. However, procedural biotechnology experts stand to lose monetarily if such changes occur.

While the debate surrounding physician reimbursement continues, we must maintain our efforts to enhance child healthcare on the local, regional, and national levels. Participation in organizations such as school boards, PTAs, and youth groups affords us the opportunity to serve our communities. In addition to such "grass roots" activism, membership in osteopathic professional organizations provides us with an avenue to effect change. The American College of Osteopathic Pediatricians (ACOP) is one organization whose primary focus is to foster and stimulate improvement in all areas of child health and well-being. The ACOP, which marks its 50th year in 1990 , welcomes all licensed physicians interested in children's health as members.

As of now, NOM week may be over, but our commitment to meet the challenge of children growing up healthy should know no time constraints.

RONALD V. MARINO, DO

Special focus editor

Dr Marino is Director of Ambulatory and Behavioral Pediatrics at Winthrop-University Hospital, Mineola, NY, and a member of the JAOA Editorial Advisory Board.

\section{AOA joins fight against sexually transmitted diseases}

While the AIDS epidemic commands the attention of the medical community and the media, the incidence of other sexually transmitted diseases (STDs) quietly festers. The incidence of Chlamydia, genital herpes, gonorrhea, genital warts, and syphilis is increasing at an alarming rate in the United States: According to the Centers for Disease Control (CDC), the number of syphilis cases increased from approximately 70,000 in 1986 to 103,000 in 1988. The incidence of drug-resistant strains of gonorrhea rose from 22,000 in 1987 to 31,000 cases in 1988. Each year, approximately 3 to 4 million Chlamydia infections occur. Likewise, 750,000 new cases of genital warts and 500,000 cases of symptomatic genital herpes are diagnosed annually.

These statistics reveal only part of the problem. The real crux of the issue can be attributed, in part, to public misinformation. A survey commissioned by the Burroughs Wellcome Co found that of the polled 632 adults between the ages of 18 and 49 , $62 \%$ never questioned a sexual partner or potential partner about having an STD. Twenty-seven percent believed that STDs can be contracted from a toilet seat or other surface, and $12 \%$ thought that a person cannot contract STDs through a single sexual encounter with a familiar companion.

This survey represents part of an educational campaign designed to encourage sexually active individuals to conduct a regular genital self-examination (GSE ${ }^{(\pi)}$ ). Recognizing the importance of this campaign, the American Osteopathic Association, along with the American College of General Practitioners in Osteopathic Medicine and Surgery (ACGPOMS); the American Academy of Dermatology; the American Academy of Family Physicians; and the American Social Health Association, has joined the Burroughs Wellcome Co in its education efforts.

To shed light on this current health crisis, the sponsors have produced a pamphlet, "Genital SelfExamination GSE Guide." The pamphlet describes, in easy-to-understand language, the causes and symptoms of the five major STDs previously mentioned. It details a step-by-step self-examination procedure in which men and women can check themselves for possible STD signs and symptoms. Patients who think they may have an STD are encouraged to seek medical attention, not only for diagnosis and treatment, but for advice on how to prevent the spread of the disease. Physicians may

(continued on page 1132 ) 


\section{AMERICAN OSTEOPATHIC ASSOCIATION}

\section{AMBULATORY CARE- THE CHALLENGE OF OSTEOPATHIC MEDICINE}

94th Annual

Convention

and Scientific Seminar

ACADEMY OF OSTEOPATHY

ADDICTIONOLOGY

ALLERGY AND IMMUNOLOGY

DERMATOLOGY

EMERGENCY MEDICINE

GENERAL MEDICINE

INTERNAL MEDICINE

NEUROPSYCHIATRY

PATHOLOGY

PREVENTIVE MEDICINE

REHABILITATION MEDICINE

RESEARCH CONFERENCE

RHEUMATOLOGY

SCLEROTHERAPY

SPORTS MEDICINE

AUXILIARY

Registration, Exhibits and

Didactic Sessions-

Anaheim Convention Center

\section{Hotels:}

Anaheim Hilton and Towers

Hyatt Regency Alicante

Inn at the Park

Quality Hotel

Holiday Inn of Anaheim

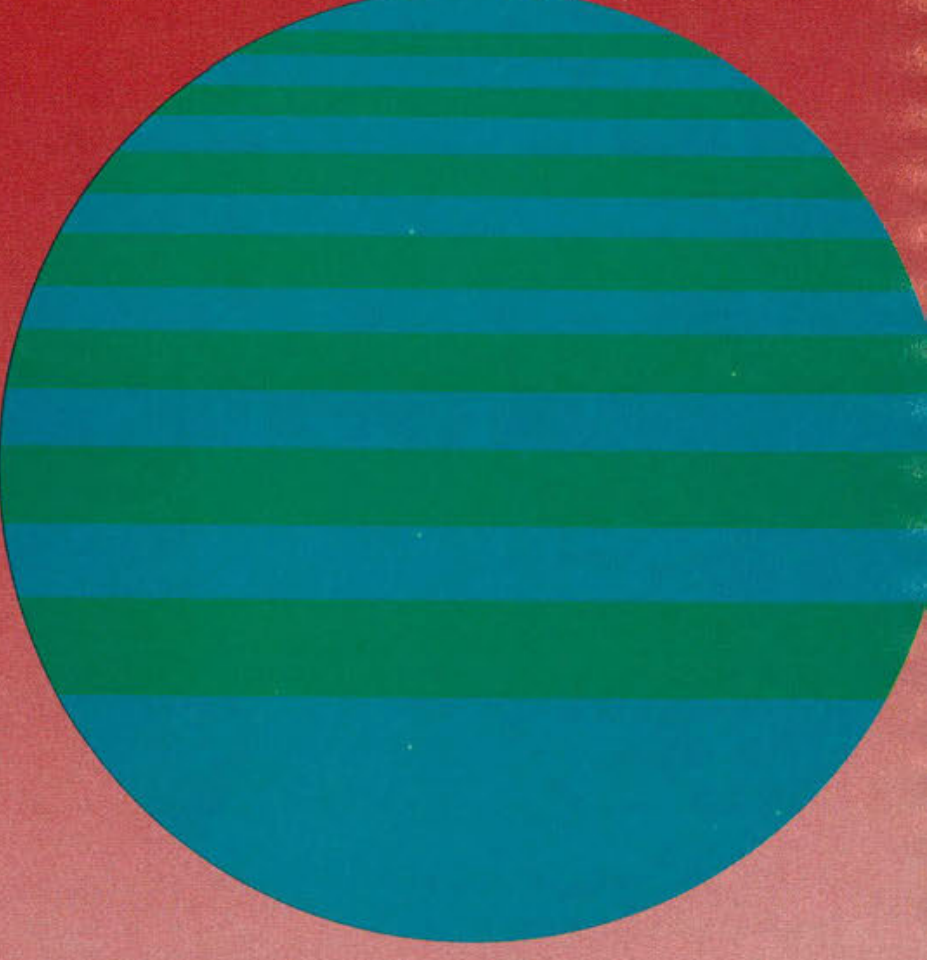



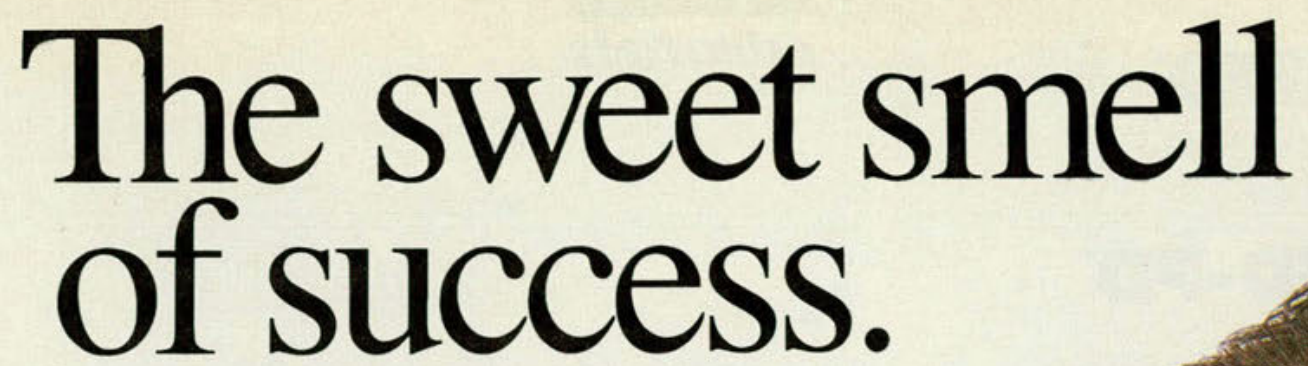

Bromfed provides your patients fast, symptomatic relief of seasonal and perennial rhinitis associated with nasal congestion, hay fever and sinusitis.

Bromfed contains a well-tolerated antihistamine, brompheniramine maleate, for effective relief of rhinorrhea, sneezing and watery eyes. Bromfed combines this with an effective decongestant, pseudoephedrine $\mathrm{HCl}$, for the relief of congestion due to swollen nasal mucosa.

Bromfed has a timed-release formula that permits convenient b.i.d. dosing. It is also available as Bromfed-PD ${ }^{\infty}$ Timedrelease Capsules (brompheniramine maleate $6 \mathrm{mg}$ and pseudoephedrine $\mathrm{HCl} 60 \mathrm{mg}$ ), Bromfed ${ }^{\circledR}$ Tablets (brompheniramine maleate $4 \mathrm{mg}$ and pseudoephedrine $\mathrm{HCl} 60 \mathrm{mg}$ ) and

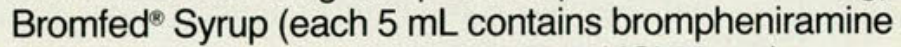
maleate $2 \mathrm{mg}$ and pseudoephedrine $\mathrm{HCl} 30 \mathrm{mg}$ ).

Please see adjacent page for brief summary of prescribing information.

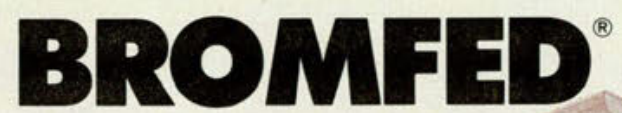

TIMED-RELEASE CAPSULES

(brompheniramine maleate $12 \mathrm{mg}$ and pseudoephedrine $\mathrm{HCl} 120 \mathrm{mg}$ ) 
TIMED-RELEASE CAPSULES

brompheniramine maleate $12 \mathrm{mg}$ and

pseudoephedrine $\mathrm{HCl} 120 \mathrm{mg}$ )

\section{BROMFED-PD}

TIMED-RELEASE CAPSULES

(brompheniramine maleate $6 \mathrm{mg}$ and

pseudoephedrine $\mathrm{HCl} 60 \mathrm{mg}$ )

\section{The sweet smell of success.}

\section{Effective decongestant.}

Well-tolerated antihistamine.

Convenient b.i.d. dosing.

\section{Briet Summary}

CONTRAINDICATIONS Hypersensitivity to any of the ingredients. Also contraindicated in patients with severe hyMAO inhibitor therapy, patients with narrow-angle glaucoma, urinary retention, peptic ulcer and during an asthmatic attack.

WARNINGS Considerable caution should be exercised in patients with hypertension, diabetes mellitus, ischemic heart disease, hyperthyroidism, increased intraocular pressure and prostatic hypertrophy. The elderly (60 years or older) are more likely to exhibit adverse reactions.

Antihistamines may cause excitability, especially in children. At dosages higher than the recommended dose, nervousness, dizziness or sleeplessness may occur.

PRECAUTIONS General: Caution should be exercised in patients with high blood pressure, heart disease, diain patients with high blood pressure, heart disease, diamay exhibit additue eftects with other CNS dis product including alcohol.

Information for Patients: Antihistamines may cause drowsiness and ambulatory patients who operate machinery or motor vehicles should be cautioned accordingly.

Drug Interactions: MAO inhibitors and beta adrenergic blockers increase the effects of sympathomimetics. Sym pathomimetics may reduce the antihypertensive effects of methyldopa, mecamylamine, reserpine and veratrum alkaloids. Concomitant use of antihistamines with alcohol and other CNS depressants may have an additive effect.

Pregnancy: The safety of use of this product in pregnancy has not been established.

ADVERSE REACTIONS Adverse reactions include drowsiness, lassitude, nausea, giddiness, dryness of the mouth, blurred vision, cardiac palpitations, lushing, in creased irritability or excitement (especially in children).

Dosage and Administration

BROMFED CAPSULES Adults and children over 12 years of age: 1 capsule every 12 hours.

BROMFED-PD CAPSULES Children 6 to 12 years of age: 1 capsule every 12 hours.

BROMFED TABLETS Adults and children 12 and over: One tablet every 4 hours not to exceed 6 doses in 24 hours. Children 6 to 12 years: One-half tablet every 4 hours not to exceed 6 doses in 24 hours. Do not give to children under 6 years except under the advice and supervision of a physician.

CAUTION: FEDERAL (U.S.A.) LAW PROHIBITS DISPENSING WITHOUT A PRESCRIPTION.

BS -4000

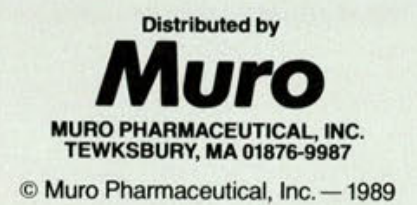

MU BR-1109 obtain free copies of this pamphlet by calling ( 800 ) 234-1124, or by writing to: GSE, PO Box 4088, Woburn, MA 01888-4988.

The osteopathic medical community remains committed to this educational campaign. David Condoluci, DO, panel member and AOA delegate, and Royce Keilers, DO, President of the ACGPOMS, represented our profession at the press conference, which kicked off this campaign on July 20.

As promoters of health and disease prevention, we have an obligation to do more than pass out these pamphlets. As Dr Condoluci emphasizes, "We need to constantly stimulate dialogue so that people feel comfortable talking about these diseases, so that they feel comfortable enough to seek medical attention early."

THOMAS WESLEY ALLEN, DO 